\title{
Research on the influence of the strip tension on contact stress and cold rolling force with a strain-hardening
}

\author{
K Ilin ${ }^{1,2}$ and G Baranov ${ }^{1}$ \\ ${ }^{1}$ Ural Federal University named after the first President of Russia B N Yeltsin, 19, \\ Mira St., Yekaterinburg, 620002, Russia \\ E-mail: ${ }^{1}$ k.v.ilin@urfu.ru
}

\begin{abstract}
The influence of strip tension on contact stress and cold rolling force with strainhardening has been investigated by using a numerical method. Dependences between roll pressure and strip tension for one rolling case have been studied. A comparison of the results provided by an introduced method to the already known methods allowed measurements of inaccuracy when the arc of contact has been replaced by chord and whenthe yield strength value for each step has been replaced by the average value of yield strength. Approaching to the real shape of the deformation zone and step-by-step calculations of strain-hardening increases magnitudes of average normal stress and rolling force. The highest difference between obtained results in comparison with the introduced method and already known methods reaches the largest value in the case with intensely hardening steels without strip tension. The increase of strip tension shows less difference between methods. The introduced method lets to calculate the rolling force for different metals depending on strip tension with more precision. Obtained results of the numerical analysis of the influence strip tension on the average normal stress and rolling force were summarized in the form of functions convenient for engineering calculations, with inaccuracy less than $5 \%$.
\end{abstract}

\section{Introduction}

Strip tension one of the important factors defining energy intensity, rolling force and contact stresses during cold strip rolling. Contact stress during the rolling process depends on geometric parameters of deformation zone, mechanical characteristics of the material, interfacial friction, front and back tension [1]. Cold rolling is characterized by low interfacial friction and angle of bite less than 8 degrees. These facts are in consent with the application of strip theory for the metal stress analysis [2$10]$.

According to the method proposed by A Tselikov [1] for computing contacts stresses, the arc of contact replaced by chord and start strip tensions are taken into account via coefficients $\xi_{i}$ :

$$
\begin{aligned}
& \text { for backward slip zone: } p_{A}=\left(\frac{2 \tau_{S}}{\delta}\right)\left[\left(\xi_{0} \delta-1\right)\left(\frac{h_{0}}{h_{x}}\right)^{\delta}+1\right] \\
& \text { for forward slip zone: } p_{B}=\left(\frac{2 \tau_{S}}{\delta}\right)\left[\left(\xi_{1} \delta+1\right)\left(\frac{h_{x}}{h_{1}}\right)^{\delta}-1\right]
\end{aligned}
$$


where: $\tau_{S}=\frac{2 \sigma_{S}}{\sqrt{3}}-$ pure shear stress; $\sigma_{S}=\frac{\sigma_{S 0}+\sigma_{S 1}}{2}-$ average yield stress; $\sigma_{s 0}$ and $\sigma_{s 1}-$ yield stress before and after the draft; $\delta=\mu \operatorname{Ctg}\left(\frac{\alpha}{2}\right) ; \mu$ - friction coefficient; $\alpha-$ angle of bite; $\xi_{0}=\frac{2 \tau_{S}-\sigma_{A}}{2 \tau_{S}}$; $\xi_{1}=\frac{2 \tau_{S}-\sigma_{B}}{2 \tau_{S}} ; \sigma_{A}$ and $\sigma_{B}-$ strip tension stress before and after deformation zone; $h_{0}-$ strip thickness before the draft respectively; $h_{1}$ - strip thickness after the draft; $h_{x}$ - current value of strip thickness.

The average normal stress is defined by the equation:

$$
p_{c p}=\frac{1}{l} \int_{0}^{l} p_{x} d x
$$

where $l$ - arc length.

To simplify calculations of average normal stress, the following equation [1] is used:

$$
p_{c p}=\frac{1}{\Delta h}\left(\xi_{0} 2 \tau_{S 0} \frac{h_{0}}{\delta-2}\left[\left(\frac{h_{0}}{h_{H}}\right)^{\delta-2}-1\right]+\xi_{1} 2 \tau_{S 1} \frac{h_{1}}{\delta+2}\left[\left(\frac{h_{H}}{h_{1}}\right)^{\delta+2}-1\right]\right)
$$

where $\Delta h$ - metal draft; $\tau_{S 0}$ and $\tau_{S 1}$ - pure shear stress before and after the draft respectively; $h_{H}-$ strip thickness at the neutral plane.

According to the method introduced by U Hessenberg and R Sims, average normal stress which includes the influence of strip tension is defined by the following equation:

$$
p_{c p}=p_{c p}^{\prime}\left(1-0,25 \frac{\sigma_{A}-\sigma_{B}}{\tau_{S}}\right)
$$

where $p_{c p}^{\prime}$ - average normal stress without strip tension.

A Korolev presented another simplified equation [8]:

$$
p_{c p}=p_{c p}^{\prime}-0,5\left(\sigma_{A}+\sigma_{B}\right)
$$

When average normal stress is defined by equations (1)-(3) and (5)-(6), and metal hardening has been taken into account via the average value of pure shear stress and the arc of contact replaced by chord, which may lead to imprecision [10].

As follows from equations (5)-(6), front and back strip tensions effect equally at rolling force. That inconsistent with already known experimental data, according to this data, back strip tension effects more at rolling force than front strip tension [1-2]. Already existing methods of assessment of strip tension influence usually connected with a particular case of the rolling process, which makes it difficult using them for engineering design $[2,11]$.

\section{The new method for computing contact stress}

The aim of this paper is the investigation of the influence of strip tension stress before and after deformation zone at contact stresses and rolling pressure during cold rolling metal strips with different parameters of strain-hardening. Determination of dependency of rolling pressure from strip tension, estimating imprecision from replacing arc of contact by chord and equivalent yield stress by average yield stress.

In this method arc of contact was replaced by a lot of numbers of small chords, while mechanic characteristics of metal in these spaces were set up as average value. Using equations (1) and (2), the recurrent relations between contact stresses at the beginning and the end of each space have been obtained: 


$$
\begin{aligned}
& \text { for backward slip zone: } p_{A i}=\left(\frac{2 \tau_{S i}}{\delta_{i}}\right)\left[\left(\xi_{A i} \delta_{i}-1\right)\left(\frac{h_{i}}{h_{i+1}}\right)^{\delta_{i}}+1\right] \\
& \text { for forward slip zone: } p_{B i}=\left(\frac{2 \tau_{S i}}{\delta_{i}}\right)\left[\left(\xi_{B i} \delta_{i}+1\right)\left(\frac{h_{i+1}}{h_{i}}\right)^{\delta_{i}}-1\right]
\end{aligned}
$$

where $\tau_{S i}=\frac{2 \sigma_{S i}}{\sqrt{3}}-$ pure shear stress at $i$ step; $\sigma_{S i}=\frac{\sigma_{i}+\sigma_{i+1}}{2}-$ average yield stress at $i$ step; $\sigma_{i}-$ yield stress at beginning of $i$ step; $\xi_{A i}=\frac{2 \tau_{S i} \pm \sigma_{A i}^{\prime}}{2 \tau_{S i}} ; \sigma_{A i}^{\prime}=p_{A i-1}-2 \tau_{S i} ; \xi_{B i}=\frac{2 \tau_{S i} \pm \sigma_{B i}^{\prime}}{2 \tau_{S i}} ; \sigma_{B i}^{\prime}=p_{B i-1}-2 \tau_{S i}$; $\delta_{i}=\frac{\mu}{\operatorname{tg} \varphi_{i}} ; \varphi_{i}=\alpha-\frac{\left(1+2 i^{\prime}\right) \alpha}{2 \gamma}-$ the angle between the chord and rolling axis at $i$ step; $i^{\prime}=0 \ldots i-1 ; h_{i}-$ the height of the strip at beginning of $i$ step; $\gamma$ - number of chords;

Height of the strip has been defined by the equation:

$$
h_{i}=h_{1}+2 R\left(1-\operatorname{Cos}\left(\frac{\alpha}{\gamma} i\right)\right)
$$

where $R$ - radius of roll; $i$ change from $\gamma$ to 0 for equation (7) and from 0 to $\gamma$ for equation (8). The strain-hardening determination has been defined by the equation:

$$
\sigma_{S i}=\sigma_{S 0}\left(1+m \varepsilon^{n}\right)
$$

where $m$ and $n$ - coefficients of hardening curve; $\varepsilon=\ln \left(\frac{h_{0}}{h_{i}}\right)$ - deformation ratio.

According to the aforementioned method using equations (7)-(8), contact stress and average normal stress for different values of front and back strip tension for steel $65 \mathrm{G}$ and steel 10 were found, and the obtained results were compared to the results provided via equations (1)-(4).

Plots of contact stress for rolling with parameters: $R=275 \mathrm{~mm} ; \mu=0.12 ; \lambda=1.5 ; h_{1}=3 \mathrm{~mm}$ are presented in figures 1-2, where plots 1 and 2 have been calculated by equations (1)-(2) and (7)-(8) respectively, without strip tension, and plots 3 and 4 have been calculated by equations (1)-(2) and (7)-(8) respectively, with strip tension $q_{0}=q_{1}=0,5$; where: $q_{0}=0,5\left(\frac{\sigma_{A}}{\tau_{s 0}}\right) ; q_{1}=0,5\left(\frac{\sigma_{B}}{\tau_{s 1}}\right)$.

The relationship between the average normal stress and strip tension has been measured by the coefficient $v=\frac{p_{c p}}{p_{c p}^{\prime}}$. The value of $p_{c p}^{\prime}$ was defined by equation (3) using equations (7)-(8).

Plots presenting the dependence of $v$ from $q_{0}$ and $q_{1}$ for steel $65 \mathrm{G}$ for the aforementioned rolling parameters and different strip tensions are shown in figures 3-5. Plot 1 has been defined by equations (7)-(8), plot 2 by (1)-(2), and plot 3 by equation (4).

The same computing was made for steel 10. As the result, it has been established that the magnitude of $v$ coefficient for steel $65 \mathrm{G}$ without strip tension calculated by equations (7)-(8) was higher for about $19 \%$ than by equations (1)-(2) and 34\% higher than coefficient magnitude defined by equation (4). For steel 10 difference between methods amounted to $10 \%$ and $24 \%$ respectively. Higher strip tension shows less difference between methods. 


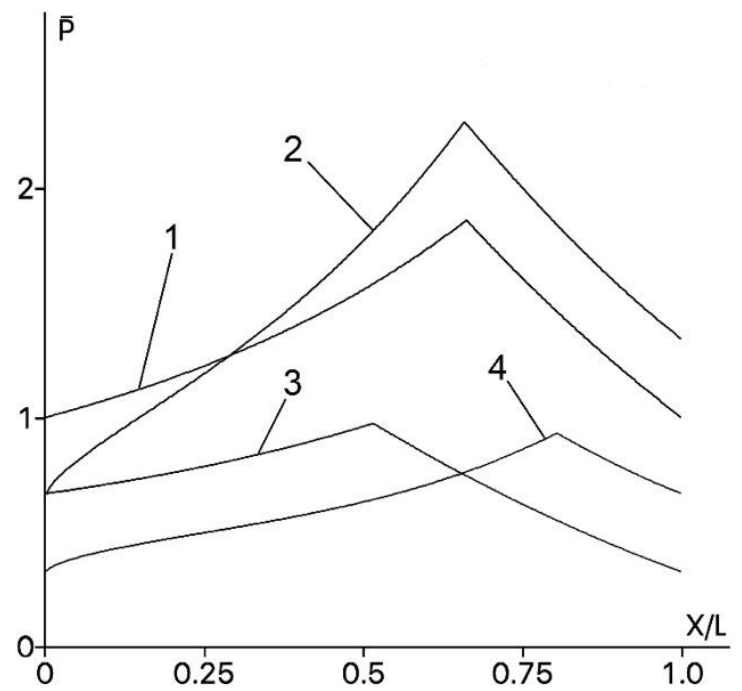

Figure 1. Plots of contact stress for steel 10 with $m=1.86$ and $n=0.64$.

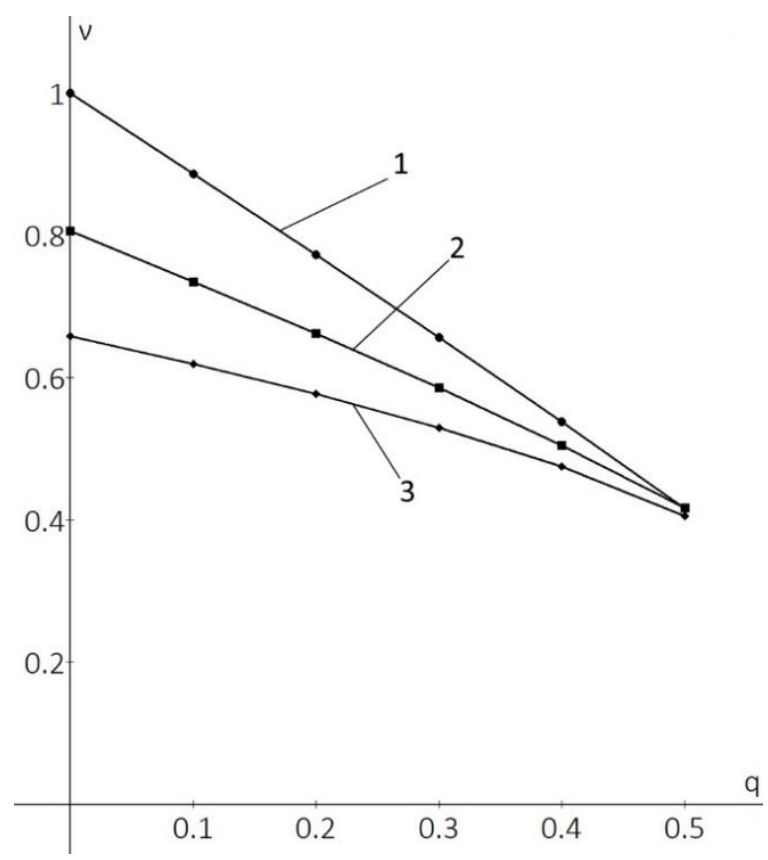

Figure 3. Plots of dependence $v$ from $q_{0}$ and $q_{1}$ for steel $65 \mathrm{G}$.

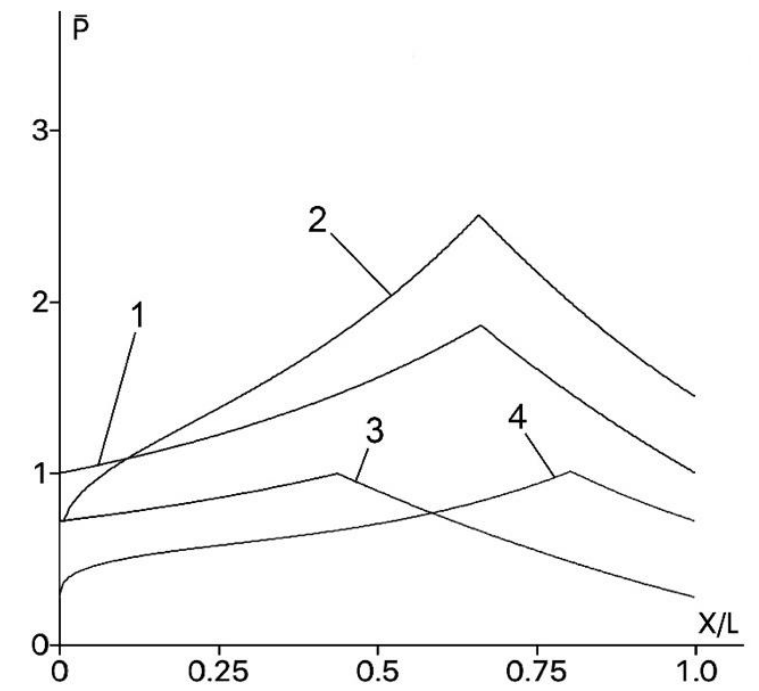

Figure 2. Plots of contact stress for steel $65 \mathrm{G}$ with $m=2.2$ and $n=0.35$.

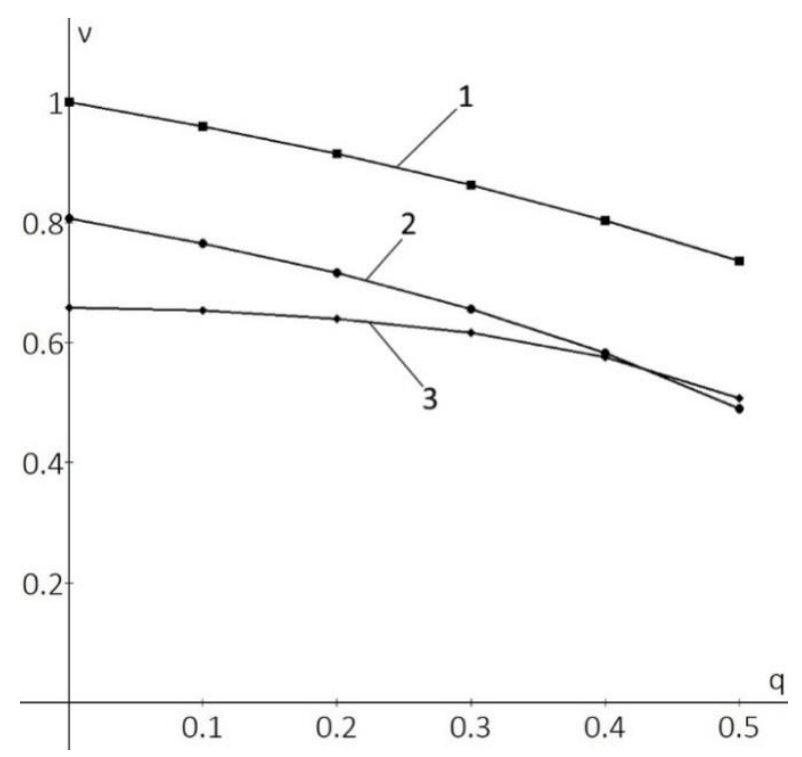

Figure 4. Plots of dependence $v$ from $q$ with front tension of strip for steel $65 \mathrm{G}$. 


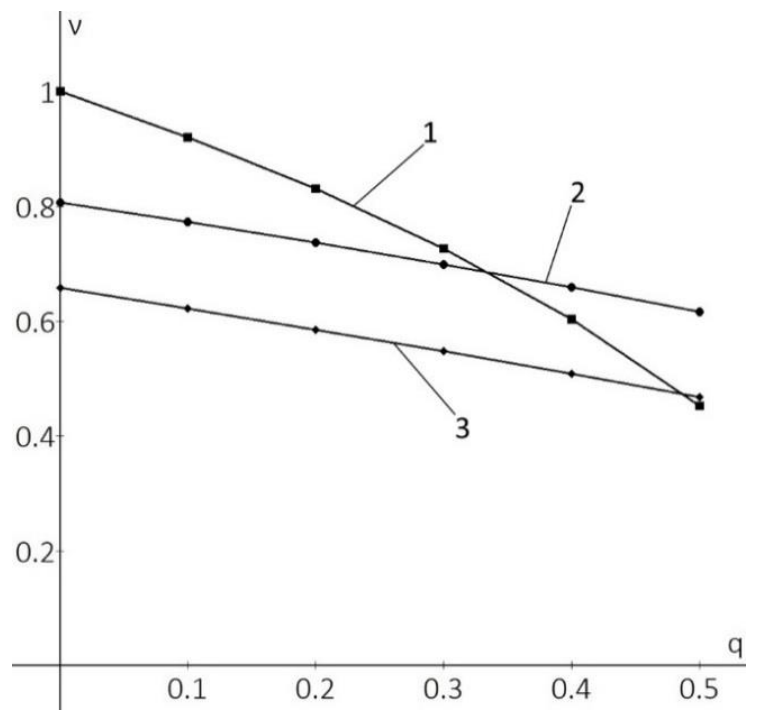

Figure 5. Plots of dependence $v$ from $q$ with back tension of strip for steel 65G.

Analysis of influence rolling process parameters and exponent of hardening curve $n$ on coefficient $v$, made with using introduced model showed that $\lambda$ in the range from 1.1 till 2.5 and $\delta$ in the range from 1.6 till 6 in the case when only front strip tension exists, inconsiderable effects on $v$ and dependence $v$ from $q_{l}$ and may be approximated with inaccuracy less than $5 \%$ via equation $v=v_{1}=1-0,47 q_{1}^{1,15} n^{-0,23}$. In the case when only back strip tension exists influence $n$ on $v$ may be neglected approximating results via equation $v=v_{0}=1-q_{0}^{1,2} \delta^{0,07}$. In the case when front and back strip tension exists coefficient $v$, with inaccuracy mentioned above, approximating via equation

$$
v=v_{0}-\left(1-v_{1}\right)\left(1-1,5 q_{0}\right)
$$

Obtained theoretical results well within already exist experimental data $[1-2,12]$ and provide considering the influence of strip tension with more precision.

\section{Conclusions}

The investigation of the influence of front and back strip tension at contact stresses and rolling forces during cold rolling of metal has been performed, plots of dependence rolling force from strip tension were made, and the obtained results were compared with results provided by already known methods. Approaching to the real shape of the deformation zone and step-by-step calculations of strainhardening increases magnitudes of average normal stress and rolling force. The highest difference between obtained results in comparison with the introduced method and already known methods amounts to $34 \%$ in the case with intensely hardening steels without strip tension. The increase of strip tension shows less difference between methods. Obtained results of the numerical analysis of the influence strip tension on the average normal stress and rolling force were summarized in the form of functions convenient for engineering calculations.

\section{References}

[1] Tselikov A I, Nikitin G S and Rokotian S E 1980 Theory of longitudinal rolling (Moscow: Metallurgiya) p 320

[2] Vasilev Ya D 2012 Theoretical study of influence tension on energy efficiency of cold strip rolling process Izv. Vuzov. Chernaya metalluriya vol 6 pp 3-5

[3] Durnev V D and Nastich V P 2000 Influence of strip tension on the stress distribution in the deformation source in cold rolling Russian Metallurgy (Metally) vol 4 pp 55-59

[4] Inatovich U V and Gareeva L V 2018 Influence of strip tension on drafting schedule during cold 
strip rolling Proizvodstvo prokata vol 11 pp 3-6

[5] Tselikov A I, Tomlenow A D and Zuzin V I 1982 Theory of rolling: handbook (Moscow: Metallurgiya) p 335

[6] Nikitin G S 2009 Continuous Rolling Theory: schoolbook (Moscow: Bauman Moscow State Technical University) p 399

[7] Treryakov A V 1966 Theory, calculation and research of cold rolling mills (Moscow: Metallurgiya) p 250

[8] Korolev A A 1969 Design and calculation of machines and mechanisms of rolling mills (Moscow: Metallurgiya) p 462

[9] Baranov G L 2015 Improved Calculation of the Contact Stress in Strip Rolling Steel in translation vol 45 issue 6 pp 447-52

[10] Baranov G L 2018 Influence of Strain Hardening on the Force in Cold Strip Rolling Steel in translation vol $\mathbf{4 8}$ issue $\mathbf{1 1}$ pp 739-44

[11] El-Bitar T A 1993 Computer program for the calculation of roll force and torque with strip tension in cold rolling $I \& S M$ vol 20 (5) pp 87-96

[12] Chernov P P, Muhin U A and Bahaev K V 2005 Influence of interstand tension mode on specific energy consumption during cold rolling Trudy VI Kongressa prokatchikov (Lipetsk) pp 186-90 